\title{
MODEL NURSING EARLY WARNING SYSTEM SCORE (NEWSS) DENGAN APLIKASI TEHNOLOGI INFORMASI SEBAGAI PENGKAJIAN DETEKSI KEGAWATAN PADA KLIEN STROKE DI RS KABUPATEN TANGERANG
}

\author{
Sunardi, Een Sukaedah \\ Politeknik Kesehatan Kemenkes Banten \\ Korespondensi: candisurowono70@gmail.com
}

\begin{abstract}
Stroke is a clinical syndrome, occurs suddenly, progressively, rapidly, and there is a decrease in neurological function even to death. The main treatment of stroke clients is to maintain adequate cerebral blood flow (CBF) oxygenation. Early detection of emergency risks that may arise due to changes in cerebral circulation must be done quickly and accurately. Therefore in need of an innovation to record the emergency risk detected of stroke client treated in an ordinary ward. Early Warning System Scoring (EWSS) on stroke clients going to be developed is an early warning detection of the risk of emergencies. By looking at appropriate data recorded periodically the clinical risk level of stroke patients treated could be assessed. The purpose of this study is to establish necessary elements to assess accurately the clinical stroke risk level. The design of this research is Quasi experiment to test NEWSS recording model on stroke client with information technology bases. NEWSS-Stroke Application element as the research variable and risk of stroke gravity will be the dependent variable. The NEWSS-Stroke element are: Level of awareness, NIHSS Value, Body Temperature, Blood Pressure, Mean Atrial Pressure (MAP), Breath Frequency, Pulse Frequency and blood gas analysis (pCO2, pO2, O2 Arterial Saturation, and $\mathrm{O} 2$ peripheral Saturation $(\mathrm{SaO} 2))$. These information will be inputted to the recording system. The preliminary study show that these element is valid and reliable with value greater than $r$ value in table 0,869 . The conclusion is the NEWSS-Stroke application can detect the risk of a stroke client's treated in an ordinary ward. Further research is currently being carried out on a larger samples in different Hospital.
\end{abstract}

Keywords: Stroke NEWSS, digital application 


\begin{abstract}
ABSTRAK
Stroke merupakan sindroma klinis, terjadi mendadak, progresif, cepat, dan terjadi penurunan fungsi neurologi bahkan sampai menimbulkan kematian, penangganan utama pada klien stroke adalah mempertahankan oksigenasi cerebral atau cerebral blood flow (CBF) secara adequate. Deteksi dini adanya resiko kegawatan yang mungkin muncul akibat perubahan sirkulasi cerebral harus dilakukan dengan cepat dan tepat. Oleh karena di perlukan sebuah inovasi recording hasil deteksi resiko kegawatan pada kasus stroke saat dirawat diruang rawat biasa. Salah satunya menggunakan kemajuan teknologi dalam bentuk aplikasi berbasis tehnologi informasi. Early Warning System Scoring (EWSS) pada klien stroke, adalah sebuah deteksi peringatan dini resiko adanya kegawatan sehingga dengan melihat recording yang tepat secara periodik dapat menilai tingkat resiko klinis pasien stroke yang dirawat. Tujuan recording aplikasi NEWSS yang sedang dikembangkan pada klien stroke yang dirawat, yaitu dapat menetapkan elemen yang diperlukan untuk menilai tingkat resiko klinis klien stroke secara akurat (valid dan realiabel). Desain penelitian ini adalah Quasi Eksperimen yaitu mengujicoba model recording dengan aplikasi NEWSS pada klien stroke berbasis tehnologi informasi. Variabel penelitian yaitu elemen Aplikasi EWSS-Stroke dan variable dependen adalah resiko tingkat kegawatan stroke dan upaya tindak lanjutnya. Data diinput secara langsung oleh perawat dari hasil pemeriksaan dan observasi yang telah dilakukan. Adapun elemen aplikasi NEWSS-Stroke yaitu; Tingkat kesadaran, Nilai NIHSS, Suhu Tubuh, Tekanan Darah, Mean Atrial Pressure (MAP), Frekwensi Nafas, Frekwensi Nadi dan hasil pemeriksaan analisa gas darah $\left(p \mathrm{CO}_{2}, p \mathrm{O}_{2}\right.$, Saturasi $\mathrm{O}_{2}$ Arteri, Saturasi $\mathrm{O}_{2}$ perifer $\left(\mathrm{SaO}_{2}\right)$ ). Berdasarkan hasil penelitian bahwa elemen/komponen data yang dimasukan kedalam aplikasi NEWSS adalah valid dan realiabel dengan niai $r$ hasil lebih besar dari nilai $r$ dalam tabel 0,869, dari 35 jumlah sample yang ada. Kesimpulannya adalah aplikasi NEWSS-Stroke ini dapat mendeteksi resiko kegawatan klien stroke yang dirawat diruang biasa. Penelitian lanjutan saat ini sedang dilakukan pada jumlah sampel yang lebih banyak dengan variasi Rumah Sakit Yang berbeda.
\end{abstract}

Kata kunci: NEWSS Stroke, aplikasi digital

\section{PENDAHULUAN}

Kasus stroke saat ini merupakan penyebab kematian nomor satu dihampir semua Rumah Sakit di Indonesia, data april 2016 sebesar 14,5\%, dimana pada tahun 1990an diurutan keempat (Pusdatin kemenkes 2016). Diperkirakan pada tahun 2020 prevalensi penderita stroke meningkat 2 kali lipat (YASTROKI, 2016). Jumlah klien stroke diperkirakan meningkat setiap tahunnya, Riskesdas Tahun 2007, menunjukan kasus stroke dimasyarakat yang

Jurnal Medikes, Volume 5, Edisi 2, November 2018 
terdeteksi yaitu $85,7 \%$ dan prevalensi stroke pada perempuan lebih tinggi dari pada lakilaki. hasil Riskesdas tahun 2013 kasus stroke berdasarkan wawancara (berdasarkan jawaban responden yang pernah didiagnosis nakes dan gejala) juga meningkat dari 8,3 per 1000 (2007) menjadi 12,1 per 1000 (2013), dari data-data diatas menunjukan angka prevalensi stroke meningkat pada tiap tahunnya. Di Rumah Sakit Kabupaten Tangerang, didapatkan data bahwa pada sepuluh bulan terakhir sampai dengan desember 2016, klien dirawat dengan Stroke Non Hemoragik (SNH) sebanyak 166 orang dengan angka kematian sebanyak 50 orang, sedangkan Stroke Hemoragik (SH) sebanyak 89 orang dengan angka kematian sebanyak 24 orang.

Memperhatikan data-data diatas serta angka kematian yang ada di Rumah Sakit Kabupaten Tangerang menunjukan rata-rata angka kematian antara 40 - 55\% dari angka klien yang dirawat, hal ini meyakinkan bahwa benar adanya trend jumlah kematian klien stroke meningkat, hal ini penting menjadi perhatian karena otak merupakan salah satu organ vital sebagai kontrol aktifitas hidup manusia. Otak mendapat 20\% dari curah jantung artinya aliran darah secara global serebral dialiri volume darah per menit per 100 gram jaringan otak, rata-rata bila terjadi peningkatan tekanan kadar $\mathrm{CO}_{2}$ (pCO2) $1 \mathrm{mmHg}$ dimungkinkan terjadi peningkatan darah 1-2 cc pada CBF dan ini akan terjadi perubahan peningkatan volume darah di otak (Black \& Hawk, 2014). Sedangkan ketika tekanan darah meningkat terjadi kontriksi pembuluh darah dan menurunkan darah ke otak tetapi bila tekanan darah menurun maka pembuluh darah akan dilatasi untuk meningkatkan darah ke otak tentu saja hal ini akan mempengaruhi TIK (Patria et al. 2006).

\section{Early Warning System Skoring} (EWSS) adalah sebuah sistem monitoring dengan skoring fisiologis yang umumnya digunakan di unit medikal bedah sebelum pasien mengalami kondisi kegawatan. Skoring EWSS disertai dengan algoritme tindakan berdasarkan hasil skoring dari pengkajian pasien. (Duncan \& McMullan, 2012; Graham M.T, 2012). EWSS berorientasi bagaimana mendeteksi kegawatan sebelum adanya kejadian. Oleh karena itu pentingnya sistem pengkajian yang cepat untuk dapat mendeteksi awal adanya kegawatan pada klien stroke.

\section{Nursing Warning System Skoring} (NEWSS) adalah penerapan sistem skoring deteksi dini terhadap kegawatan kondisi klien 
sebelum terjadi disuatu unit ruang perawatan (Duncan \& Mc.Mullan, 2012), Penelitian dan aplikasi tentang NEWSS sudah mulai banyak diakukan dibeberapa Rumah Sakit diantaranya RS Fatmawaty Jakarta, RSCM Jakarta dan beberapa Rumah Sakit lain yang fungsinya dalah melengkapai Tim Medis Reaksi Cepat (TMRC) atau dalam tim Code Blue (Firmansyah, 2013).

NEWSS Memiliki karakteristik Tools data yang hampir sama dari setiap RS atau unit ruang tetapi yang membedakan adalah masing-masing unit perawatan disesuaikan dengan klien yang dirawat (Kyriacos U, Jelsma J, James M, Jordan S, 2014), semisal di ruang medikal bedah (Dewasa) akan berbeda dengan Unit Penyakit jiwa dan lainnya. Sedangkan NEWSS terkait stroke sampai saat ini belum didapatkan sumber NEWSS yang diaplikasikan dalam aplikasi tehnologi informasi.

Pada Klien dengan stroke oksigenasi cerebral adalah faktor paling penting dalam menentukan kondisi stroke dan kelangsungan kondisi cerebral pada klien stroke, bahwa oksigenasi cerebral dipengaruhi oleh beberapa faktor, diantaranya; suhu tubuh, tekanan darah dan Mean Atrial Pressure (MAP), adanya peningkatan TIK. Tandatanda vital merupakan kondisi yang dapat dideteksi dengan melakukan pengkajian yang terus menerus, cepat dan tepat, dengan pengembangan model EWSS berbasis tehnologi informasi dapat dijadikan sistem yang memantau adanya fluktuasi sirkulasi oksigen yang mengalami perubahan dan menpengaruhi TIK seiring adanya vasodilasi dan vasospasme pembuluh darah otak sebagai media CBF (Stocchetti et al. 2013). Sedangkan suhu tubuh pertama kali berpengaruh terhadap metabolisme, dimana regulasi metabolisme tergantung pada perubahan Oksigen $\left(\mathrm{O}_{2}\right)$ dan Carbondiaksida $\left(\mathrm{CO}_{2}\right)$, ketika $\mathrm{O}_{2}$ rendah dan $\mathrm{CO}_{2}$ tinggi menyebabkan vasodilatasi regulasi CSF, dimana produksi CSF menurun atau meningkatkan reabsorpsi CSF sehingga dapat meningkatkan dan menurunkan TIK, (Helleberg et al. 2014).

Berdasarkan data-data, dan hasil penelitian terkait stroke dan kondisi yang dapat mempengaruhi oksigenasi cerebral pada klien yang mengalami stroke, oleh karena itu dalam melakukan monitoring terhadap perubahan-perubahan hemodinamik tubuh serta melakukan intervensi keperawatan dalam mempertahankan tingkat oksigenasi secara tepat, cepat untuk mengurangi angka kesakitan dan kematian pada klien stroke yang dirawat sangatlah 
penting. Penelitian ini ingin menghasilkan model NEWSS dengan aplikasi tehnologi informasi sebagai pengkajian deteksi kegawatan pada klien Stroke di RS.

Berdasarkan latar belakang diatas, maka masalah penelitian yang dapat dirumuskan adalah sebagai berikut: "Apakah Model NEWSS dengan Aplikasi Tehnologi informasi pada klien stroke dapat mendeteksi kegawatan klien stroke di RS Kabupaten Tangerang". Berdasarkan rumusan masalah tersebut, maka pertanyaan penelitian yang ingin diajukan dalam penelitian ini adalah apakah model NEWSS dengan aplikasi tehnologi informasi dapat mendeteksi kegawatan pada klien stroke iskemik dan hermoragik di ruang rawat RS Kabupaten Tangerang.

\section{METODE}

Desain penelitian yang digunakan dalam penelitian ini adalah kuasi ekperimen. Studi quasi eksperimen merupakan salah satu rancangan penelitian yang dipergunakan untuk mencari hubungan sebab akibat dari satu kejadian (polit, 2005; Alatas H, 2006). Dan mengaplikasikan model NEWSS pada klien stroke.

Penelitian telah dilakukan dua tahap selama 2 tahun, pada tahap pertama tahun
2017 dilaksanakan di RSU Kabupaten Tangerang. Sedangkan tahap kedua pada tahun 2018 penelitian di RSU Tangerang dan RSP Fatmawati. Populasi pada penelitian ini adalah semua klien Stroke iskemik dan hemoragik yang dirawat diruang rawat RSU Kab.Tangerang. Sampel penelitian yaitu: klien yang dirawat di ruang rawat RSU Kab.Tangerang, yang telah memiliki kriteria inklusi dan eklusi.

Kriteria inklusi dalam penelitian ini adalah sebagai berikut: 1) klien stroke iskemik dan hemoragik hari pertama dan atau kedua dirawat di Rumah Sakit, 2) klien mengalami stroke pertama dan atau kedua kalinya, 3) Usia klien 30-65 tahun, 4) Derajat stroke ringan - berat (penentuan derajat berat-ringanya stroke dengan menggunakan Skala NIHSS), 5) Diagnosa stroke oleh medis, 6) Tidak disertai infeksi otak (meningitis dan encephalitis). Sedangkan kriteria eklusi sebagai berikut: 1) klien stroke iskemik dan hemoragik hari ketiga dirawat, 2) klien mengalami stroke ketiga kalinya, 3) Usia klien < 29 tahun dan > 66 tahun, 4) Terdapat tumor intrakranial, 5) diagnose penyakit selain stroke, disertai infeksi otak (meningitis dan encephalitis).

Teknik pengambilan sampel yaitu dengan proporsional sampel, yaitu teknik 
Sunardi,dkk. Model Nursing Early Warning System Score.

sampling yang menentukan jumlah sampel dari populasi yang memiliki ciri tertentu sampai jumlah kuota (jatah) yang diinginkan terpenuhi, di mana klien stroke yang termasuk ke dalam kriteria inklusi berpeluang sama untuk dijadikan responden. Setelah responden memenuhi krieria yang telah ditetapkan didapatkan hasil di RSUD Tangerang sebanyak 64 responden dan di RS Fatmawati sebanyak 63 responden. Sesuai ketentuan jumlah sampel minimal adalah 710 kejadian untuk tiap parameter (Peduzzi et al. dalam Hosmer dan Lemeshow, 2000). Penelitian ini memiliki 8 variabel yang akan diteliti, jadi jumlah sampel minimal yang dibutuhkan adalah $8 \times(8-10)=50-72$ responden, dari ketiga Rumah Sakit yang menjadi tempat penelitian. Jadi sampel total dai kedua RS adalah 127 sehingga sudah memenuhi syarat sampel minimal.

Penelitian ini menggunakan intrumen pengumpulan data dan menggunakan alat ukur yang sudah dikalibrasi, yaitu: Intrumen pengumpulan data, yaitu: Program aplikasi NEWSS Stroke berbasis tehnologi informasi (web) dan Alat pengukur: Spignomanometer automatik, Thermometer digital, pen-light (merk \& jenis sama), alat pengukur saturasi Oksigen external (Oxymetry). Dan pengumpulan data dilaksanakan secara

Jurnal Medikes, Volume 5, Edisi 2, November 2018 bertahap sampai dengan analisa hasil penelitian.

\section{HASIL}

Model ini telah diteliti pada 35 responden sebagai uji coba awal dan pada tahun 2018 sebanyak 127 klien, dan hasil penelitian terdiri dari dua bagian dari analisis univariat, yaitu karakteristik responden dan uji realibility terkait komponen data dalam model NEWSS. Berdasarkan jenis kelamin bahwa dari 127 responden, sebanyak 56 responden adalah perempuan $(44,1 \%)$, lakilaki sebanyak 71 responden $(55,9 \%)$, dari hasil penelitian ini menunjukan bahwa jenis kelamin laki-laki lebih banyak mengalami stroke, hal ini berbanding lurus dengan teori bahwa kejadian pada stroke adalah laki-laki (Morton, 2005). Dan berdasarkan hasil penelitian didapatkan rata-rata usia responden adalah 52,00 tahun dengan simpangan baku sebesar 11.171, dan diyakini 95\% responden berusia antara 50,69 tahun sampai dengan 59,71 tahun. Sedangkan berdasarkan usia jumlah responden paling banyak adalah dengan stroke iskemik/Stroke Non Hemoragik dengan jumlah 67 dari 127 orang $(52,8 \%)$. Berdasarkan jenis stroke jumlah responden paling banyak adalah 
dengan nilai NIHSS $<5$ dengan jumlah 101 dari 127 orang $(79,5 \%)$.

Distribusi Tingkat/Resiko klinis kegawatan, berdasarkan tabel 3.1 jumlah responden paling banyak adalah kondisi normal atau hijau sebanyak 54 responden (42,5\%), sedang tingkat kegawatan dengan kondisi gawat atau merah sebanyak 18 responden $(14,2 \%)$.

Tabel 3.1

Distribusi tingkat/resiko klinis kegawatan dengan NEWSS, pada klien Stroke di RS $(n=127)$ nilai $\mathrm{r}$ table (lampiran) dengan menggunakan $\mathrm{df}=\mathrm{n}-2(127-2=125)$, pada tingkat kemaknaan $5 \%$, didapat angka $\mathrm{r}$ table $=0,174$, sehingga dapat disimpulkan bahwa dari 7 pertanyaan, diatas $r$ table rata-rata 0,362 oleh karena itu dinyatakan valid. Sedangkan hasil uji reliabilitaas didapatkan nilai r Alpha $(0,727)$ lebih besar $\mathrm{r}$ pada table $(0,174)$, sehingga 7 elemen pertanyaan termasuk indikator kegawatan stroke semua reliabel.

Tabel 3.2 merupakan analisis dari hasil survey terkait dengan penggunaan aplikasi NEWSS dengan aplikasi online dan

\begin{tabular}{lccr}
\hline Tingkat Kegawatan & Frekuensi & \% & apl \\
\hline Stabil (Hijau) & 54 & 42,5 & man \\
Perhatian (Kuning) & 32 & 25,2 & \\
Perhatian Ketat (Orange) & 23 & 18,1 & \\
Gawat (Merah) & 18 & 14,2 & \\
\hline Jumlah & 127 & 100,0 & \\
\hline
\end{tabular}

Pengujian komponen data dalam

aplikasi tehnologi informasi pada model

NEWSS, dilakukan uji validitas dan

reliabilitas, adapun hasil uji validitas dengan

Tabel 3.2

Distribusi pengunaan aplikasi NEWSS online dan manual di $\mathrm{RS}(\mathrm{n}=21$ )

\begin{tabular}{|c|c|c|c|c|c|}
\hline \multirow[t]{2}{*}{ No } & \multirow[t]{2}{*}{ Sistem NEWSS secara Umum } & \multicolumn{2}{|c|}{ NEWSS Online } & \multicolumn{2}{|c|}{ NEWSS Manual } \\
\hline & & Frek (Ya) & $\%$ & Frek (Tdk) & $\%$ \\
\hline 1 & Kecepatan dalam dokumentasi & 21 & 100 & 21 & 100 \\
\hline 2 & Kecepatan dalam melihat tampilan scoringnya & 21 & 100 & 21 & 100 \\
\hline 3 & $\begin{array}{l}\text { Dokumentasi EWSS menghabiskan kertas sangat } \\
\text { banyak }\end{array}$ & 21 & 100 & 21 & 100 \\
\hline 4 & Hasil dokumentasi disimpan dalam sistem terukur & 21 & 100 & 21 & 100 \\
\hline 5 & Hasil dokumentasi dapat diakses dengan mudah & 21 & 100 & 21 & 100 \\
\hline 1 & $\begin{array}{l}\text { Cepat dan otomatis dapat dilihat hasil scoringnya } \\
\text { Hasil akhirnya harus dihitung scoringnya }\end{array}$ & 21 & 100 & 21 & 100 \\
\hline 2 & Lebih mudah recording/pencatatannya & 21 & 100 & 21 & 100 \\
\hline 3 & Tampilan scoring dari setiap pasien dapat dilihat & 21 & 100 & 21 & 100 \\
\hline 4 & dimanapun dan kapanpun. & & & & \\
\hline & Kedepan dapat ditampilkan pada layar monitor & 21 & 100 & 21 & 100 \\
\hline 5 & lebar yang diletakkan di Ners Station) & 21 & 100 & 21 & 100 \\
\hline
\end{tabular}

Jurnal Medikes, Volume 5, Edisi 2, November 2018 
Pada table 3.2 didapatkan hasil bahwa dari 21 pengguna NEWSS dengan berbasis Online/TI menyatakan bahwa secara umum sistem yang digunakan atau yang diuji cobakan $100 \%$ memudahkan dalam scoring dan prosesnya cepat dan dapat dipantau secara real time.

\section{PEMBAHASAN}

Berdasarkan hasil penelitian didapatkan karakteristik responden, yaitu berdasarkan jenis kelamin bahwa dari 127 responden, sebanyak 56 responden adalah perempuan $(44,1 \%)$, laki-laki sebanyak 71 responden $(55,9 \%)$, dari hasil penelitian ini menunjukan bahwa jenis kelamin laki-laki lebih banyak mengalami stroke, hal ini berbanding lurus dengan teori bahwa kejadian pada stroke adalah laki-laki (Morton, 2005).

Pada teori lain dijelaskan bahwa penyebab terjadinya stroke dipengaruhi oleh beberapa faktor diantaranya, usia, suku, pola hidup,stressor dan lain-lain (Brunner \& Suddart, 2014), dimungkinkan terjadi pada jenis kelamin perempuan seperti pada penelitian yang dilakukan tahun 2017, tetapi tidak ekstrem perpedaan hal ini masih cukup rasional teori yang mengatakan bahwa kejadian stroke dapat terjadi pada perempuan karena faktor stressor, pola hidup dan suku tersebut (Brunner \& Suddart, 2014). Berdasarkan hasil penelitian, responden menurut usia, bahwa usia yang mengalami stroke terjadi pada umur 52 tahun, dengan rata-rata umur 53 tahun. dan dari kesimpulan didapatkan bahwa diyakini usia yang mengalami kejadian stroke hemoragik antara umur 28 tahun sampai 86 tahun.

Pada gambaran karakterik usia, dapat disimpulkan bahwa angka kejadian stroke hemoragik, rata-rata usia tersebut menunjukan pergeseran dari dewasa tua ke usia dewasa muda, hal ini memungkinkan karena perubahan pola hidup dan prilaku hidup sehat (Gan, 2008). Secara teori terjadi pada umur dewasa tua dan usia lanjut, hal ini sesuai dengan teori bahwa pada umur tersebut terjadi penurunan fungsi struktur organ (Smeltzer \& Bare, 2013; Black \& Hawks).

Sedangkan dari hasil penelitian terkait jenis stroke didapatkan jenis stroke iskemik yang terbanyak yaitu 67 responden $(52,8 \%)$ dari 128 responden sedangkan sebanyak 60 responden dengan stroke hemoragik $(47,2 \%)$. Bila dilihat dari hasil data bahwa berdasarkan teori kedua jenis stroke yang terjadi sesuai dengan hasil jurnal bahwa antara stroke iskemik dan hemoragik hampir tidak ada 
beda angka kejadiannya (Smeltzer \& Bare, 2013; Black \& Hawks). Sedangkan berdasarkan karakteristik nilai NIHSS bahwa responden paling banyak adalah dengan nilai NIHSS < 5 dengan jumlah 101 dari 127 orang $(79,5 \%)$, hal ini merupakan hal yang masih sanagat rasional karena dari beberapa kasus score NIHSS adalah kurang dari score lima.

Bila melihat dari nilai NIHSS yang rata-rata kurang dari lima relevan dengan kondisi resiko klinis tingkat kegawatan klien stroke yang dirawat di RS, yang didapatkan responden paling banyak adalah kondisi normal atau hijau sebanyak 54 responden $(42,5 \%)$, sedang tingkat kegawatan dengan kondisi gawat atau merah sebanyak 18 responden $(14,2 \%)$.

Hasil uji validitas dan relibialitas terhadap tujuh elemen/komponen yang menjadi fokus pertanyaan sebagai basis data pada program aplikasi NEWSS stroke, yaitu; Tingkat kesadaran, Frekwensi nafas, Nadi, Respirasi, Suhu, Tekanan darah sistolik dan diastolik, serta Mean Atrial Presure (MAP) menunjukan bahwa semua valid dan reliabilitas, secara keseluruhan hal yang dipertanyaan sebanyak tujuh pertanyaan adalah valid.
Elemen data pada peneltian sebelumnya sebanyak sembilan item tetapi dengan masukan dan efektifitas dari sebuah aplikasi NEWSS, maka ada dua item yang dikeluarkan dari sistem scoring yaitu scoring NIHSS dan pemeriksaan AGD. Tanda-tanda vital yaitu frekwensi nadi, nafas, suhu tubuh semua mengambarkan bila terdapat perubahan dari tanda-tanda vital tersebut secara fluktuatif sangat berpengaruh pada kondisi stroke. Sesuai dengan teori dan hasil beberapa penelitian bahwa peningkatan suhu tubuh dimungkinkan dapat meningkatkan TIK, sehingga dapat digolongkan sebagai indicator tingkat kegawatan pada klien stroke, tetapi hal ini tidak berpengaruh langsung. Suhu tubuh yang meningkat merupakan interpretasi dari meningkatnya metabolisme tubuh, dengan peningkatan metabolisme tubuh, kebutuhan oksigen juga meningkat, dimana kenaikan suhu satu $\left(1^{0}\right)$ dapat meningkatkan kebutuhan oksigen 10\%, sehingga hal ini akan mempengaruhi oksigenasi ke serebral, fluktuasi sirkulasi oksigen mengalami perubahan dan dapat mempengaruhi TIK seiring adanya vasodilasi dan vasospasme pembuluh darah otak sebagai media CBF (Stocchetti et al. 2013).

Hal penting lain adanya perubahan TIK adalah tekanan perfusi serebral/cerebral 
perfusion pressure (CPP). CPP adalah jumlah aliran darah dari sirkulasi sistemik yang diperlukan untuk memberi oksigen dan glukosa yang adekuat untuk metabolisme otak (Black \& Hawks, 2014). CPP dihasilkan dari tekanan arteri sistemik rata-rata dikurangi tekanan intrakranial, dengan rumus $C P P=M A P-I C P . C P P$ normal berada pada rentang 60-100 mmHg. MAP adalah rata-rata tekanan selama siklus kardiak. MAP = Tekanan Sistolik $+2 \mathrm{X}$ tekanan diastolik dibagi 3. Jika CPP diatas $100 \mathrm{mmHg}$, maka potensial terjadi peningkatan TIK. Jika kurang dari $60 \mathrm{mmHg}$, aliran darah ke otak tidak adekuat sehingga hipoksia dan kematian sel otak dapat terjadi (Morton et.al, 2005). Jika MAP dan ICP sama, berarti tidak ada CPP dan perfusi serebral berhenti, sehingga penting untuk mempertahankan kontrol ICP dan MAP (Black \& Hawks, 2014).

Walaupun dalam hasil penelitian yang dilakukan oleh Stefan Schwarz, Dimitrios Georgiandis, Alfred Aschoff and Stefan Schweb yang berjudul "Effect of body position (head of bed elevation) on intracranial pressure and cerebral perfusion in patients with large haemorraghic stroke". Penelitian ini dilakukan pada 18 pasien stroke Iskemik akut yang dirawat di

Jurnal Medikes, Volume 5, Edisi 2, November 2018 neurocritical care unit. Indikator evaluasi adalah nilai GCS, pupil, tekanan darah, denyut nadi, frekuensi pernapasan, suhu tubuh, tekanan intrakranial, MAP (mean arteri pressure), Middle cerebral artery (MCA) peak mean flow velocity $\left(\mathrm{V}_{\mathrm{m}} \mathrm{MCA}\right)$, tekanan perfusi serebral. Semua pasien terpasang intubasi, ventilator, terpasang monitor tekanan TIK, MAP dan MCA peak mean flow velocity dengan intracranial ultra sound.

Pada hasil survey pengguna aplikasi NEWSS online sebanyak 21 pengguna (Perawat) menyatakan bahwa sistem aplikasi yang dibuat memberikan kemudahan, kecepatan dan dapat dimonitor secara real time, sehingga hasil dapat cepat didapatkan dengan melihat hasil monitor yang ada di android atau dimonitor computer, disamping itu juga bahwa kinerja dapat dilihat dari hasil kerja yang diimput ke sistem. Tentunya dengan sistem ini mengurangi jumah kertas yang dibutuhkan untuk mendokumentasikan hasil monitor NEWSS.

\section{SIMPULAN}

Berdasarkan hasil penelitian yang dilakukan dapat disimpulkan bahwa insiden stroke terjadi pada usia antara 28-86 tahun, 
dan jenis stroke yang banyak terjadi yaitu stroke non perdarahan $(\mathrm{SNH})$ dan terjadi pada jenis kelamin laki-laki. Penelitian ini telah mendapatkan hasil bahwa komponen/elemen data NEWSS yang dapat diaplikasikan dalam aplikasi berbasis tehnologi informasi adalah Tingkat kesadaran (AVPU), Frekwensi Nafas, frekwensi nadi, Tekanan darah, MAP dan Suhu, dengan hasil uji validitas dan reliabelitas, dengan nilai $r$ hasil lebih besar dari $\mathrm{r}$ tabel, 0,727. dimana tingkat resiko klinis kegawatan dengan program aplikasi NEWSS berbasis tehnologi informasi pada klien stroke dikategorikan dalam empat indikator kegawatan, yaitu; normal/stabil (warna hijau dengan hasil skoring 0-2), perhatian (warna kuning dengan hasil skoring 3-4), perhatian ketat (warna Orange dengan hasil skoring 5-6), sedangkan kondisi gawat (warna merah dengan hasil skoring > 7). Survey yang dilakukan pada 21 penguna (perawat) bahwa aplikasi berbasis tehnologi/online NEWSS, semua menyatakan bahwa aplikasi NEWSS lebih cepat, tepat, terukur dalam menilai tingkat resiko klinis kegawatan klien stroke.

$$
\begin{aligned}
& \text { Rekomendasi klinis dari hasil } \\
& \text { penelitian bahwa protap pelaksanaan } \\
& \text { pemantaun secara periodik dan terencana. }
\end{aligned}
$$

Untuk mengatipasi adanya perubahan tingkat kegawatan secara dini dengan menggunakan program Aplikasi

NEWSS berbasis tehnologi informasi dapat digunakan dan dimanfaatkan oleh RS terutama perawat dalam perawatan seharihari, selanjutnya hasil penelitian dapat menjadi standar pelaksanaan pemantauan/observasi yang lebih baik terutama pada klien stroke di tatanan klinik baik bagi mahasiswa maupun dosen keperawatan medikal bedah. Penelitian ini dapat dilanjutkan dengan meneliti variabel lain yang diperkirakan dapat berpengaruh terhadap kondisi kegawatan klien stroke.

\section{DAFTAR PUSTAKA}

AHA/ASA, 2015. Gudelines stroke 2015; Stroke. 2015;46:000-000, American Heart Association, Inc. http:// stroke.ahajournals.org.

Black, Joice. M., \& Hawk, Jane. H.2013. Medical Surgical Nursing; clinical management for positive outcomes. ( $8^{\text {th }}$ Ed.), St. Louis: Elsevier. Inc

Duncan, K. \& McMullan, C. (2012). Early Warning System. Philadelphia: Lippincott Williams \& Wilkins.

Firmansyah (2013), NEWSS: Nursing Early Warning Scoring System, TMRC RSCM diakses dari website: https://www.scribd.com/doc/1840935 
56/NEWSS-Nursing-Early-WarningScoring-System

Ginsberg L, 2008. Neurologi; Lecture Notes $\left(8^{\text {th }}\right.$ ed.). alih bahasa Wardhani. Malang; Penerbit Erlangga.

Helleberg et al. 2014. Mechanisms, predictors and clinical impact of early neurological deterioration: the protocol of the Trondheim early neurological deterioration study: BMC Neurology 2014, 14:201, diambil pada 13 Juni 2016 dari http://www.biomedcentral.com/14712377/14/201.

Patria et.al, 2006. Cerebrovascular dynamics with head of bed elevation in patients with mild or moderate vasospasme after aneurisma subarachnoid hemoragik. American Journal of Critical care. Vol. 56.

Peter Cristian S.dr. 2015. Modified Early Warning Score (MEWS) for clinical deterioreation diakses pada tanggal 21 Juni 2017 dari www.mdclc.com/modified-earlywarning-score-mews-clinicaldeteriorition.

Riskesdas, 2013, Riset Kesehatan Dasar Tahun 2013, Kemenkes; Jakarta

Sunardi, 2011. Pengaruh pemberian posisi kepala flat 0 derajat dan elevasi kepala 30 derajat terhadap tekanan intrakranial pada pasien stroke iskemik di RSCM jakarta; Jurnal Madya Poltekkes Kemenkes Jakarta III edisi, Vol.10, No.1,Juni 2011.
Sunardi, 2016. Hubungan suhu tubuh/tekanan darah terhadap tekanan intrakranial pada klien stroke hemoragik di RSU Kabupaten tangerang.

Smletzer, S.C., \& Bare, B.G. 2014. Brunner \& Suddarth's: Textbook of Medical Surgical Nursing. Philadelphia: Lippincott.

Stocchetti et al. 2013. Clinical review: Neuromonitoring - an update: Critical Care 2013, 17:201, diambil pada 13 Juni 2016 dari http://ccforum.com/content/17/1/201. Kyriacos U, Jelsma J, Jordan S. 2011. Monitoring Vitals Signs using early warning scoring system: a review of the literature: Journal of Nursing Management, 2011. 19, 311-330.

Kyriacos U, Jelsma J, James M, Jordan S (2014) Monitoring Vital Signs: Development of a Modified Early Warning Scoring (Mews) System for General Wards in a Developing Country. PLoS ONE 9(1): e87073. doi:10.1371/journal.pone.0087073

Jurnal Medikes, Volume 5, Edisi 2, November 2018 